\title{
Calling and Emotional Well-being: Mediation by Promotion Focus and Job Crafting
}

\author{
DaYeon Her $^{1}$ \\ ${ }^{1}$ Department of Psychology, Miami University, Ohio, USA \\ Correspondence: DaYeon Her, Department of Psychology, Miami University, Ohio, USA.
}

Received: September 9, 2019

Accepted: October 2, 2019

Available online: October 17, 2019

doi:10.11114/ijsss.v7i6.4512

URL: https://doi.org/10.11114/ijsss.v7i6.4512

\begin{abstract}
Teachers' emotional well-being is incredibly crucial for both teachers themselves and children. When considering this importance, researchers need to explore ways to enhance teachers' emotional well-being. Before developing an invention program, however, it requires performing in-depth research to give fundamental data for intervention. As part of its efforts, thus, this study intends to examine whether promotion focus and job crafting have a mediation effect on the relationship between calling and emotional well-being. For this purpose, this study collected data from 337 elementary school teachers. Subsequently, the current work administered four scales measuring calling, promotion focus, job crafting, and emotional well-being to them. The findings found that promotion focus and job crafting showed full mediation effects on the relationship between calling and emotional well-being, respectively, with a sequential mediation of promotion focus and job crafting. Finally, this paper critically discusses the implication of which researchers and leaders should be aware and then suggests directions for future researchers.
\end{abstract}

Keywords: calling, promotion focus, job crafting, emotional well-being, elementary school teachers

\section{Introduction}

Recently, there are rapidly growing concerns over the emotional well-being of teachers in South Korea (KEDI, 2018; Shin, 2019, May 13; OECD, 2014). Indeed, teachers complain of severe stress and burnout (KEDI, 2018; Shin, 2019, May 13). Also, it is entirely incredible that teachers of South Korea among 34 OECD countries showed the highest regret for choosing a teaching profession (OECD, 2014). Out of teachers, in particular, elementary school teachers teach most of the subjects and spend with their children most of the day (Um, Joo, \& Her, 2018). Moreover, given that emotional contagion shown as a critical factor in team processes and group dynamics (Barsade, 2002; Bull Schaefer \& Palanski, 2014; Mottet \& Beebe, 2000), teachers' low emotional well-being may be directly linked to children's low emotional well-being.

Despite the concerns, unfortunately, teachers' emotional well-being has been overlooked so far (Ecclestone \& Hayes, 2009; McLaughlin, 2008). Given this reality, researchers need to make systematic efforts to enhance teachers' emotional well-being. As part of its efforts, this study attempts to conduct an in-depth study to provide essential data for an intervention program to improve teachers' emotional well-being.

Emotional well-being is the emotional state in which positive emotion is high while negative emotion is low (Kern, Waters, Adler, \& White, 2014). In a sense, emotional well-being also is the emotional aspect of subjective well-being which Diener (2000) defined as individuals' cognitive and emotional evaluation of their life. Accordingly, in subjective well-being, emotional well-being is as important as cognitive well-being. By nature, further, emotion has characteristics that go through a quicker pathway and have a more powerful memory system than cognition in the brain (LeDoux, 1996; Tyng, Amin, Saad, \& Malik, 2017). Consequently, as emotional well-being gets a competitive edge in the speed and intensity of processing information, emotional well-being is more likely to affect cognitive well-being than vice versa. As a result, whether by itself or as an antecedent of cognitive well-being, emotional well-being plays a critical role in subjective well-being.

As contributors to emotional well-being in teaching, so far, work motivation, self-esteem, social skill, and resilience have been noted (Ecclestone \& Hayes, 2009; Um et al., 2018). In this study, considering the distinctiveness of teaching, we strive to select a calling, as an independent variable, which is common among teachers and has a long and close association with teaching (Bullough \& Hall-Kenyon, 2012; Kang, 2009; Richardson \& Watt, 2006; van Vuuren, 2017). 
A calling means a moral, urgent, and identity-defining determination to aspire and pursue a transformational goal (van Vuuren, 2017). By nature, a calling connote and induce passion (Hall \& Chandler, 2004; Elangovan, Pinder, \& McLean, 2010; Vallerand et al., 2003), directly related to some factors of emotional well-being (Kern et al., 2014). Also, a calling causes intrinsic motivation (Becker, Kernan, Clark, \& Klein, 2018), leading to emotional well-being. Moreover, a high calling may lead to a strong goal pursuit (Hall \& Chandler, 2004). Like this, well, only setting and striving a goal had dramatic ramifications for an individual's emotional well-being (Emmons \& Kaiser, 1996). Indeed, an empirical study demonstrated that high commitment and goal significantly accounted for emotional well-being (Brunstein, Schultheiss, \& Grässman, 1998).

More recently, further, Dik and Shimizu (2019) suggested the perspective that a calling focused on passion may be more connected to hedonic well-being than eudemonic well-being, suggesting that the benefit varies with the form of calling. In other words, their view implies that a calling focused on passion may be directly associated with emotional well-being. In sum, as passion is inherent in a calling, a calling seems to cause emotional well-being.

Contradicting the upside of a calling, of course, some raised the downside of a calling below. First of all, individuals with a strong calling may end up burnout due to high expectations (van Vuuren, 2017). Next, assuming a calling in teachers may put a burden on them (Dill, Erickson, \& Diefendorff, 2016). Besides, it may induce a feeling of guilt in them struggling through an unanswered calling, in which a calling does not orient toward teaching (Berg, Grant, \& Johnson, 2010). At worst, bluntly requesting a calling from teachers could legitimize the unfair treatment of teachers (Kim, Campbell, Shepherd, \& Kay, 2019).

Despite the concerns, it is still difficult to deny that individuals oriented toward a calling have a more disposition to show the passion for the work which they perceive as a purpose of life (Hall \& Chandler, 2004). Indeed, they tend to show passion, motivation, and goal pursuit and thereby enjoy working (Becker et al., 2018; Dik \& Duffy, 2009; Hall \& Chandler, 2004). Based on a wide range of literature review, in the end, researchers articulated that such negative issues are due to self-management of teachers and working conditions of organizations rather than drawbacks inherent in a calling itself (Bullough \& Hall-Kenyon, 2012; Duffy, Bott, Allan, Torrey, \& Dik, 2012; Vallerand et al., 2003; van Vuuren, 2017). Taken together, we can expect that a calling causes emotional well-being.

If we pay a little more attention to earlier discussions on a calling and emotional well-being, we can infer that a calling may also cause emotional well-being through mediators (Becker et al., 2018; Brunsteinet al., 1998; Dik \& Duffy, 2009; Elangovan et al., 2010; Emmons \& Kaiser, 1996; Hall \& Chandler, 2004; Vallerand et al., 2003). Thus, we selected a promotion focus, as the first mediator, which is closely linked to passion, motivation, and goal pursuit inherent in a calling while potentially contributing to emotional well-being (Dik \& Duffy, 2009; Hall \& Chandler, 2004).

A promotion focus is one part of two self-regulation systems which Higgins (1998) posits to delineate the process of aligning oneself with one's goals. Typically, promotion-focused individuals tend to align themselves with their "ideal selves," contrast with prevention-focused individuals who incline to align themselves with their "ought selves" (Higgins, 2000; Higgins et al., 2001; Johnson et al., 2017).

The regulatory focus has a bias toward a particular orientation (Higgins et al., 2001). Nevertheless, the regulatory focus could depend upon situational factors (Higgins, 1998; Johnson et al., 2017; Kooij, Bal, \& Kanfer, 2014). According to regulatory fit theory (Higgins, 2000), motivation increases when the direction to pursue goals is the same as a regulatory focus. For example, as a calling in this study is in the same direction as a promotion focus, promotion focus is likely to cause more intrinsic motivation, eventually resulting in emotional well-being (Becker et al., 2018; Hall \& Chandler, 2004). On this basis, we expect that the promotion focus mediates the relationship between calling and emotional well-being.

Consistent with the above perspective, some evidence demonstrated that a promotion focus relates to higher emotional well-being than prevention focus (Koopmann, Lanaj, Bono, \& Campana, 2016; Lichtenthaler \& Fischbach, 2019). For example, Koopmann et al. (2016) showed that promotion focus was linked to higher emotional well-being, whereas prevention focus was linked to lower emotional well-being. In the research, especially, it is worth noting that emotional well-being was the highest when the promotion focus was high while the prevention focus was low. Such findings seem to be due to the psychological mechanisms by which a promotion focus leads to work engagement, thereby brings about a positive outcome, and ends up high positive emotion (Brunstein et al., 1998; Higgins, 1998; Higgins et al., 2001; Lichtenthaler \& Fischbach, 2019).

Next, this study picked up, as the second mediator, job crafting, that is, more proactive behavior in teaching (Kooij, Tims, \& Kanfer, 2015; Rudolph, Katz, Lavigne, \& Zacher, 2017). Job crafting is the physical and cognitive transformation that individuals make in the task or relational boundaries of their work (Wrzesniewski \& Dutton, 2001). According to Wrzesniewski and Dutton (2001), task crafting means altering the form and numbers of activities. For example, rather than merely relaxing, learning new things at work is more likely to buffer deviance which impairs well-being under 
stressors (Zhang, Mayer, \& Hwang, 2018). In a similar vein, Rudd, Aaker, and Norton (2014) also demonstrated that proactive behavior itself caused emotional well-being. Subsequently, cognitive crafting indicates modifying the way in which individuals view the job (Kooij et al., 2015), whereas relational crafting refers to using a broad discretion over people with whom one interacts (Cardador \& Caza, 2012). For instance, individuals could alter teammate's perception of their competence after expressing their distress, through reframing the distress as passion (Wolf, Lee, Sah, \& Brooks, 2016). As mentioned above, the better outcomes through job crafting may contribute to the achievement of a goal and the pursuit of meaning (Brenninkmeijer \& Hekkert-Koning, 2015; Wrzesniewski, LoBuglio, Dutton, \& Berg, 2013), ending up emotional well-being (Emmons \& Kaiser, 1996). Moreover, job crafting may be authenticity and self-expression for workers struggling through an unanswered calling and for teachers bored in teaching (Berg et al., 2010; Green, Finkel, Fitzsimons, \& Gino, 2017; Shin \& Grant, 2018).

As a rule, situational and motivational conditions are integral to craft a job (Wrzesniewski \& Dutton, 2001). Out of two conditions (Koopmann et al., 2016; Case, Bae, \& Maner, 2018), the situational condition is beyond teachers' capacity. Accordingly, a motivational condition needs to be met for teachers to craft a job. Fortunately, as a calling connotes the conditions for job crafting (Becker et al., 2018; Johnson et al., 2017; Kooij et al., 2014; Lanaj, Chang, \& Johnson, 2012; van Vuuren, 2017), it is expected that a calling brings about emotional well-being.

Like a calling, a promotion focus also may act as a motivational condition for crafting a job. The reason is because a promotion focus connotes the motivational condition (Berg et al., 2010; Higgins, 1998; Higgins et al., 2001; Johnson et al., 2017; Kooij et al., 2014; Lanaj et al., 2012; Lichtenthaler \& Fischbach, 2019; Rudolph et al., 2017; Wrzesniewski \& Dutton, 2001). Indeed, some studies demonstrated that promotion focus leads to job crafting (Brenninkmeijer \& Hekkert-Koning, 2015; Lichtenthaler \& Fischbach, 2019; Rudolph et al., 2017). Taken together, we expect that the higher the calling and promotion focus, the more the job crafting.

Drawing on the discussion so far, we aim to examine a partial mediation effect of promotion focus and job crafting on the relation between calling and emotional well-being, along with a sequential mediating effect of promotion focus and job crafting. To this end, this study sets the research model like Figure 1.

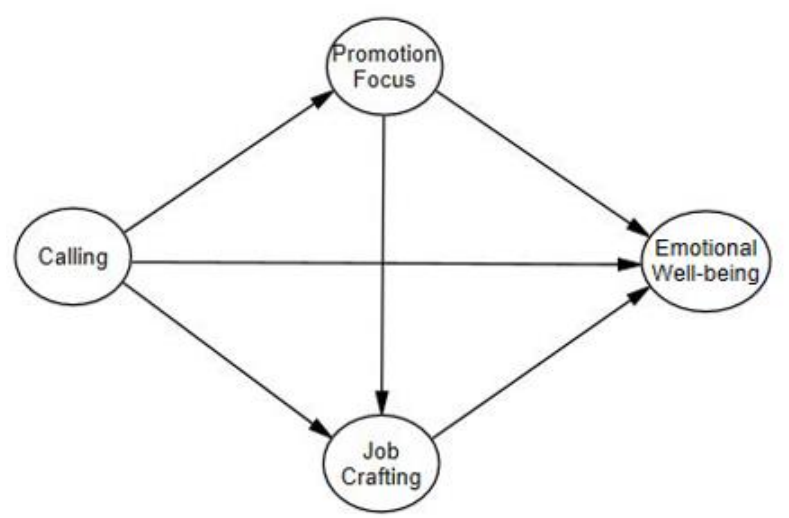

Figure 1. The research model

This research model is a partial mediation model that combines one direct path from calling to emotional well-being and three indirect paths. To be specific, indirect paths encompass two paths from calling through a promotion focus or job crafting to emotional well-being and one path from calling sequentially through a promotion focus and job crafting to emotional well-being. The hypotheses of this research model are specified as as follows.

Hypothesis 1. A calling would have a direct effect on emotional well-being.

Hypothesis 2. A promotion focus would show a mediation effect on the relationship between calling and emotional well-being.

Hypothesis 3. Job crafting would have a mediation effect on the relationship between calling and emotional well-being.

Hypothesis 4. A promotion focus and job crafting would have a sequential mediation effect on the relationship between calling and emotional well-being. 


\section{Method}

\subsection{Participants}

Participants were 337 elementary school teachers in the Seoul metropolitan area in South Korea. Participants consisted of 304 females (90.2\%) and 33 males (9.8\%). According to KEDI (2017), this gender imbalance properly reflected the overall gender ratio of South Korean elementary school teachers. Also, 179 teachers (53.1\%) were in their 20-30's, and $154(45.7 \%)$ were in their $40-50$ 's, whereas only $4(1.2 \%)$ were over their 60 's.

\subsection{Procedures}

After uploading the following four scales to Qualtrics, we posted the URL on several main communities composed of elementary school teachers in the Seoul metropolitan area. From December 24, 2018, to January 2, 2019, we recruited a total of 372 teachers with informed consent. Except for 35 data with missing values, the final data were from 337 elementary school teachers.

\subsection{Scales}

All four scales used in this study are the 5-point Likert scales from 1 (strongly disagree) to 5 (strongly agree). The higher score in each scale indicates that respondents have more calling, promotion focus, job crafting, and emotional well-being. Before calculating the scores, we recoded several items in reverse.

\subsubsection{Calling Questionnaire}

For measuring teachers' calling, this study selected the Vocation Identity Questionnaire (Dreher, Holloway, \& Schoenfelder, 2007) and then translated it under the supervision of one teacher and one professor. Through confirmatory factor analysis, this study deleted one item from a total of 9 items. After deleting the item, the goodness of fit of the scale was satisfactory or acceptable (NFI=.962, TLI=.961, CFI=.976, RMSEA=.069) (Browne \& Cudeck, 1993). The standardized factor loadings of the scale were .52 .90, implying that items validly measure each sub-factor. Cronbach's $\alpha$ coefficient was .85. The highest score of the scale is 45 points, whereas the lowest score is 9 points. There are items such as "While doing my work, I usually feel satisfied and meaningful."

\subsubsection{Emotional Well-being Scale}

To measure teachers' emotional well-being, we chose the Multidimensional Scale of Well-being (Kern et al., 2014). Next, this study translated merely two subscales measuring emotional well-being out of six subscales under the supervision of one teacher and one professor. We eliminated one item from positive emotions subscale via confirmatory factor analysis. After eliminating the item, the fit indices of the scale were satisfactory or acceptable (NFI=.974, TLI=.980, CFI=.986, RMSEA=.056) (Browne \& Cudeck, 1993). The standardized factor loadings of the scale were .57 .97, indicating that items validly measure each sub-factor. In consequence, we employed an 11-item scale consisting of positive emotions (5 items) and negative emotions (6 items). Cronbach's $\alpha$ coefficient was .86 and .94 for each subscale and .90 for the total scale. The highest and lowest scores of the scale are 55 points and 11 points, respectively. Examples of items are as follows: "Inspired (positive emotions)" and "Distressed (negative emotions)."

\subsubsection{Promotion Focus Measure}

To assess teachers' promotion focus, we selected the General Regulatory Focus Measure (Lockwood, Jordan, \& Kunda, 2002) and then extracted 9 items measuring promotion focus from an 18-item scale. Subsequently, we translated 9 items under one teacher's and one professor's direction. The fit indices of the scale in confirmatory factor analysis showed a good or satisfactory fit (NFI=.945, TLI=.967, CFI=.978, RMSEA=.043) (Browne \& Cudeck, 1993). The standardized factor loadings of the scale ranged from .48 to .72 , implying that items validly measure each sub-factor. Cronbach's $\alpha$ coefficient of this scale was .81. The highest and lowest scores of the scale are 45 and 9 points, respectively. An example of items is like: "I often think about how I will perform my work successfully."

\subsubsection{Job Crafting Scale}

For measuring teachers' job crafting, this study used the Korean Job Crafting Scale (Lee, 2017). The scale is a 15-item scale comprising task crafting (6 items), cognitive crafting (4 items), and relational crafting (5 items). Cronbach's $\alpha$ coefficient ranged from .73 to .90 for the subscales and was .88 for the total scale. The highest score of the scale is 75 , whereas the lowest score is 15 points, respectively. Examples of items are below: "When I do my job, I find a way that is most appropriate for me (task crafting)," "I think about how my job can contribute to the society (cognitive crafting)," and "I actively find a person who can give me advice on my work (relational crafting)."

\subsection{Data Analysis}

We calculated the validity and reliability of scales and then conducted hypothesis testing as follows. First, this study produced Cronbach's $\alpha$ of all scales, whereas identified validity only for scales translated, via confirmatory factor 
analysis. Next, we calculated descriptive statistics and correlations between the main variables. Finally, we verified the measurement model and the research model with Structural Equation Model. Finally, to testify the statistical significance of mediation effects, we used the bootstrapping method after creating phantom variables.

\section{Results}

\subsection{Descriptive Statistics and Correlation Coefficients}

Descriptive statistics for calling, emotional well-being, promotion focus, and job crafting and Pearson's correlation coefficients between them are shown in Table 1. There are the means, standard deviations, skewness, and kurtosis of each variable at the bottom. As the absolute values of skewness and kurtosis were less than three and seven, respectively, the assumption of normality was satisfied. All relationships between the calling, emotional well-being, promotion focus, and job crafting were significantly positive $(r=.329 \sim 559, p<.01)$. These results indicate that teachers with a higher calling, promotion focus, and job crafting tend to show higher emotional well-being.

Table 1. Descriptive statistics and correlation coefficients of the main variables

\begin{tabular}{lcrrr}
\hline Variable & 1 & 2 & 3 & \\
\hline 1. Calling & 1 & 1 & & \\
2. Emotional well-being & $.375^{* *}$ & $.405^{* *}$ & 1 & \\
3. Promotion focus & $.329^{* *}$ & $.496^{* *}$ & $.559^{* * *}$ & 1 \\
4. Job crafting & $.467^{* *}$ & 40.902 & 33.718 & 59.288 \\
M & 30.137 & 7.260 & 4.568 & 7.165 \\
Skewness & 5.520 & -.257 & -.394 & -.522 \\
Kurtosis & -.818 & .070 & 1.304 & 2.242 \\
\hline
\end{tabular}

$* p<.05$ (two-tailed). $* * p<.01$ (two-tailed).

According to the two-step approach (Anderson \& Gerbing, 1988), this study tested the measurement model before verifying the research model. The confirmatory factor analysis on the measurement model was performed after item parceling, averaging the scores of the items in sub-factors of each latent variable. To evaluate the measurement model, we used the goodness of fit indices rather than chi-square statistic, because the chi-square statistic assumes multivariate normality and is sensitive to sample size (Hooper, Coughlan, \& Mullen, 2008). As a result, NFI (.936), TLI (.924), and CFI (.956) were greater than .90, indicating a good fit. Besides, RMSEA (.077) was below .080, implying an acceptable fit (Browne \& Cudeck, 1993).

After verifying the fit of the measurement model, we examined the standardized factor loadings of the measurement model. The standardized factor loadings ranged from .46 to .81 , indicating that observed variables validly measure each latent variable. Besides, as correlation coefficients between latent variables were below .80 (.58 .79), this model did not have the multicollinearity problem.

\subsection{Verification of Research Model}

We tested the goodness of fit of the research model to verify the partial mediation effects of promotion focus and job crafting on the relationship between calling and emotional well-being (Figure 1). As a result, the fit indices were good $(\mathrm{NFI}=.936$, TLI=.924, CFI=.956) or acceptable (RMSEA=.077) (Browne \& Cudeck, 1993). Next, as a result of testifying the significance of each path, path coefficients $(\beta=.34 \sim 51, p<.05)$ were significant, except for the direct path from calling to emotional well-being $(\beta=.11, p>.05)$.

To ensure the simplicity of the model, thus, we fixed the direct path to zero and then tested the goodness of fit of the modified model. The fit indices were good (NFI=.936, TLI=.927, CFI=.956) or acceptable (RMSEA=.076) (Browne \& Cudeck, 1993). Consequently, the fit indices of the modified model were relatively higher than that of the research model (伎TLI $=.003$, 伎RMSEA $=.001$ ). Next, as a result of testifying the significance of each path, all path coefficients were significant $(\beta=.34 \sim 55, p<.05)$ (Figure 2). 


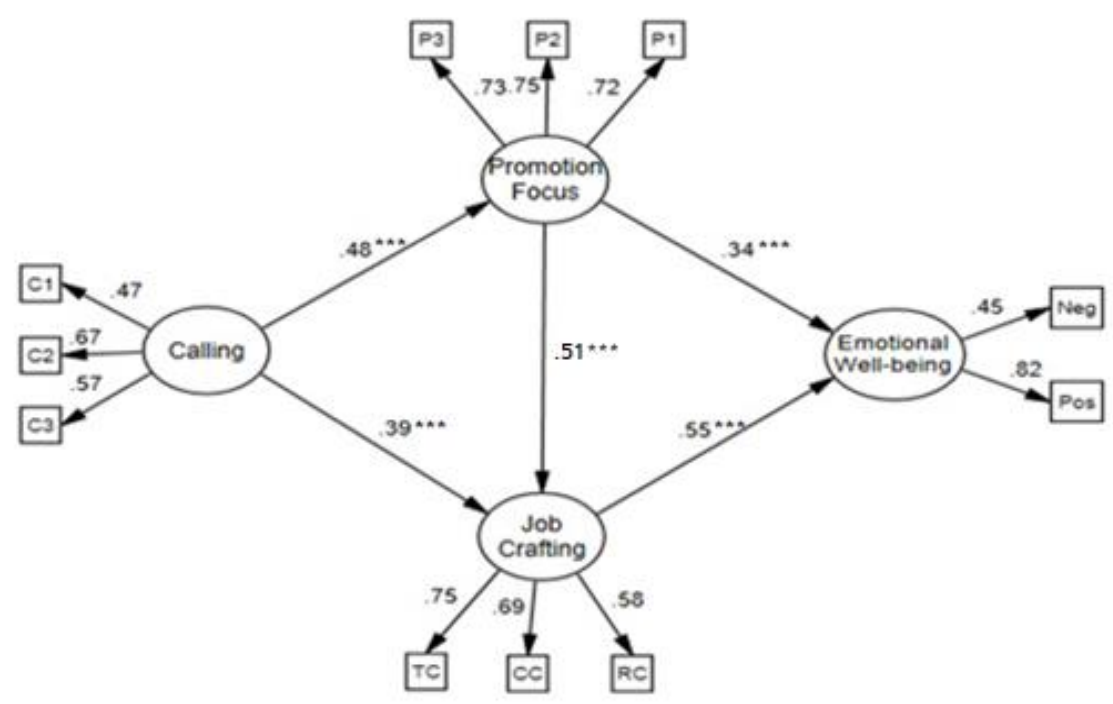

Figure 2. Path Coefficients of the Modified Model

In this model, only indirect effects were significant (.514). Subsequently, we decomposed the indirect effect by the path in relation to each hypothesis. As a result, the indirect effect was .163 in the path from calling to emotional well-being through promotion focus, .215 in the path from calling to emotional well-being mediated by job crafting, and .135 in the path from calling to emotional well-being sequentially through promotion focus and job crafting.

To confirm the statistical significance of mediation effects, we used the bootstrapping method. For this, we introduced phantom variables because AMOS provides bootstrapping only for the total mediation effect even when the model contains multiple mediators. To obtain parameter estimates, we created 2,000 bootstrap samples from raw data $(N=337)$ via random sampling.

The mediation effects of promotion focus ( $\mathrm{SE}=.098, \mathrm{CI}=.288 \sim .617)$ and those of job crafting ( $\mathrm{SE}=.041, \mathrm{CI}=.542 \sim .676)$ were significant. Likewise, the sequential mediation effect of promotion focus and job crafting ( $\mathrm{SE}=.042, \mathrm{CI}=.304 \sim .446$ ) were also significant.

As we have seen, findings supported three out of four hypotheses. Specifically, first, the path from calling on emotional well-being showed no significant effect. Second, there was a full mediation effect of promotion focus and job crafting on the relationship between calling and emotional well-being, respectively. Third, promotion focus and job crafting had a sequential mediation effect on the relationship between calling and emotional well-being.

\section{Discussion}

\subsection{General Discussion}

This paper intended to examine whether promotion focus and job crafting have a mediation effect on the relationship between calling and emotional well-being. For this purpose, four hypotheses were set, and three of them were supported, except for hypothesis 1 that a calling would have a direct effect on emotional well-being. Consequently, a promotion focus and job crafting showed a full mediation between calling and emotional well-being, respectively, with a sequential mediation of promotion focus and job crafting. The results were discussed with previous studies as follows.

Contrary to the hypothesis, first of all, a calling had not a direct effect on emotional well-being. Consequently, this hypothesis did not support the perspective (Dik \& Shimizu, 2019) that calling focused on passion would directly cause emotional well-being. Instead, the result is parallel to investigations that a calling had a positive effect on emotional well-being through psychological mechanisms such as passion, motivation, and goal pursuit (Becker et al., 2018; Brunstein et al., 1998; Duffy et al., 2012; Elangovan et al., 2010; Emmons \& Kaiser, 1996; Hall \& Chandler, 2005; Rudd et al., 2014; Vallerand et al., 2003). In short, our finding supports that, rather than going straight to emotional well-being, a calling causes emotional well-being indirectly. The specific details are below.

As expected, second, a promotion focus showed a mediation effect on the relationship between calling and emotional well-being. The finding means that teachers with a higher calling are promotion-focused and, in turn, show more emotional well-being. More specifically, in the first part of the path, it was shown that a calling led to a promotion focus positively. Little is known about an empirical study consistent with this finding, but it is explainable indirectly. In other 
words, this finding supports the perspective that passion, motivation, and goal pursuit ingrained in the calling are expressed as a promotion focus in teaching (Dik \& Duffy, 2009; Duffy et al., 2012; Elangovan et al., 2010; Hall \& Chandler, 2004; Lanaj et al., 2012; Vallerand et al., 2003; van Vuuren, 2017). In the second part of the path, a promotion focus also had a positive effect on emotional well-being. This result is consistent with the results of previous research that a promotion focus led to emotional well-being (Brunstein et al., 1998; Koopmann et al., 2016; Lichtenthaler \& Fischbach, 2019). Taken together, this finding implies that a promotion focus resulting from a calling toward teaching causes emotional well-being.

Third, as predicted, job crafting had a mediation effect on the relationship between calling and emotional well-being. It means that teachers with a higher calling tend to feel more emotional well-being via exercising more job crafting. In detail, in the former part of the path, a calling caused job crafting positively. This result supports the notion that a calling is a motivational condition of job crafting (Wrzesniewski \& Dutton, 2001). Perhaps, it is because a calling satisfied a motivational condition for crafting a job (Becker et al., 2018; Lanaj et al., 2012). In the latter part of the path, not surprisingly, job crafting showed a positive effect on emotional well-being. The finding is consistent with the results of prior research that job crafting led to emotional well-being by crafting a task, cognition, or relationship, or in other ways (Berg et al. 2010; Kooij et al., 2015; Wolf et al., 2016; Wrzesniewski et al., 2013; Zhang et al., 2018). Besides, the finding tacitly supported the process by which job crafting causes emotional well-being by goal achievement, authenticity, and self-expression (Brunstein et al., 1998; Emmons \& Kaiser, 1996; Green et al., 2017; Hall \& Chandler, 2004; Rudd et al., 2014). As a result, this finding implies that job crafting derived from teachers' calling toward teaching brought about their emotional well-being.

Finally, promotion focus and job crafting showed a sequential relationship between calling and emotional well-being. This result means that teachers with a high calling enjoy more emotional well-being by displaying a high promotion focus and thereby much crafting a job. As we already examined the path from calling to promotion focus and that from job crafting to emotional well-being, here, we focused on whether a promotion focus results in job crafting. Consequently, the finding accorded with the result of Rudolph et al. (2017) demonstrating that a promotion focus had a close link with job crafting. It seems to be because a promotion focus, like a calling, meets a motivational condition for crafting a job (Higgins, 1998, 2000; Higgins et al., 2001; Johnson et al., 2017; Kooij et al., 2014; Lanaj et al., 2012; Lichtenthaler \& Fischbach, 2019; Rudolph et al., 2017; Wrzesniewski \& Dutton, 2001).

Based on the discussion to date, we identified that a calling served as a positive psychological resource that leads to promotion focus and job crafting, ending up emotional well-being. Despite the concerns over a calling, this paper suggests that a calling still plays a critical role in emotional well-being in teaching.

\subsection{Theoretical and Practical Implications}

This study has several theoretical and practical implications. First, this study will stimulate further studies to have an interest in teachers' emotional well-being. Typically, elementary school teachers in South Korea spend with their children most of the day. In this situation, given even the contagion, processing speed, and intensity of emotion (Barsade, 2002; Bull Schaefer \& Palanski, 2014; LeDoux, 1996; Motted \& Beebe, 2000; Tyng et al., 2017), teachers' emotional well-being is indispensable to children's emotional well-being. Nevertheless, the studies on teachers' emotional well-being have been overlooked yet, while surveys (KEDI, 2018; OECD, 2014; Shin, 2019, May 13) repeatedly suggested that teachers suffer from high stress. Hence, future researchers will need to study teachers' emotional well-being profoundly, based on this work.

Second, this work will urge educational leaders to reflect on topics such as calling, promotion focus, and job crafting helpful for teachers' emotional well-being. First of all, a calling has the propensity to ooze out of someone's heart rather than the outcome which someone else requests. Unfortunately, however, a high sense of calling is being demanded of teachers in South Korea (Kang, 2009) and touted much. Like this, assuming a calling in teachers may place a psychological burden on them (Dill et al., 2016; Kang, 2009 KEDI, 2018; van Vuuren, 2017) and be a stifling factor for teachers struggling through an unanswered calling (Berg et al., 2010). At worst, bluntly requesting a calling from teachers may license the exploitative treatment of teachers (Kim et al., 2019). Based on these rationales, requesting a calling from teachers should be immediately gone. Only then would a calling be able to shine as a positive psychological resource that causes promotion focus and job crafting.

Drawing on the reflection on calling, promotion focus, and job crafting, by extension, this study will stimulate educational leaders to empower teachers so that they can display promotion focus and job crafting. Typically, teacher autonomy is a requisite for showing promotion focus and job crafting (Wrzesniewski \& Dutton, 2001). However, KEDI (2018) reported that teachers complained of a lack of teacher autonomy. For this reason, perhaps, teachers are desperate for leaders with the openness, respect, and admiration of teachers (Case et al., 2018). Thus, educational leaders need to reflect on and enhance their own leadership based on this study. Only then would teachers with a calling show 
promotion focus and job crafting.

Third, educational leaders will be able to use this research result to increase teachers' emotional well-being. Specifically, at the time when teachers face severe stress and burnout (KEDI, 2018; Shin, 2019, May 13), educational policymakers will be able to budget, coordinate the work, and reduce busywork, drawing on this study which articulates the importance of teachers' emotional well-being. Simultaneously, training program developers will design training programs to spur leaders to support teachers' promotion focus and job crafting while stimulating teachers to display promotion focus and job crafting to the fullest.

\section{Limitations and Future Directions}

This study will suggest some future directions with some limitations as follows.

First, we expect later research to explore a prevention focus in addition to a promotion focus. Indeed, most research on regulatory focus has pointed out a promotion focus as a contributor to emotional well-being (Higgins, 1998; Higgins et al., 2001; Koopmann et al., 2016; Lichtenthaler \& Fischbach, 2019). Taking one step further, however, we will find that the higher the regulatory fit in pursuing a goal, the higher the motivation, regardless of whether a promotion focus or a prevention focus (Higgins, 2000). Specifically, a calling has a better fit with a promotion focus, whereas avoidance has a better fit with a prevention focus. More intriguingly, in an interpersonal relationship such as a romantic one, it was shown that the opposite fit caused a positive relationship (Bohns et al., 2013). Therefore, future researchers need to investigate the circumstances under which prevention focus may lead to emotional well-being.

Next, further research needs to diversify samples to understand teachers in middle and high school and other countries. For example, South Korean elementary school teachers go through an exclusive training system, unlike middle and high school teachers. For that reason, they are more likely to regard teaching itself as the most rewarding and essential part of their existence (Um et al., 2018). Besides, they consist mostly of elite females, while facing heavy busywork and a shortage of autonomy. Given these considerations, there is a limitation to generalize the findings of this research to teachers differing in the training system, gender ratio, and working conditions. Therefore, it would behoove future research to explore the path through which different teachers reach emotional well-being.

\section{Conclusions}

This study identified that teachers' calling passed through promotion focus and job crafting to their emotional well-being. At the time when teachers suffer from low emotional well-being, this paper will urge educators to reflect on calling, promotion focus, and job crafting as an initial step to ultimately improve teachers' emotional well-being.

Based on the above, educational leaders should create a favorable condition for displaying teachers' promotion focus and job crafting so that a calling can lead to emotional well-being. In other words, when striving to improve working conditions and design a training program, they need to consider promotion focus and job crafting actively. Simultaneously, teachers should give full play to promotion focus and job crafting for reaching their emotional well-being. In conclusion, we hope working conditions to hit a sweet spot so that teachers can enjoy emotional well-being.

\section{Acknowledgments}

I thank HyunGyung Joo for her supervision. I also thank ByeolBee Um for helping to collect data and translate scales.

\section{References}

Anderson, J. C., \& Gerbing, D. W. (1988). Structural equation modeling in practice: A review and recommended two-step approach. Psychological Bulletin, 103(3), 411-423. https://doi.org/10.1037/0033-2909.103.3.411

Barsade, S. G. (2002). The ripple effect: Emotional contagion and its influence on group behavior. Administrative Science Quarterly, 47, 644-675. https://doi.org/10.2307/3094912

Becker, T. E., Kernan, M. C., Clark, K. D., \& Klein, H. J. (2018). Dual commitments to organizations and professions: Different motivational pathways to productivity. Journal of Management, 44(3), 1202-1225. https://doi.org/10.1177/0149206315602532

Berg, J. M., Grant, A. M., \& Johnson, V. (2010). When callings are calling: Crafting work and leisure in pursuit of unanswered occupational callings. Organization Science, 21(5), 973-994. https://doi.org/10.1287/orsc.1090.0497

Bohns, V. K., Lucas, G. M., Molden, D. C., Finkel, E. J., Coolsen, M. K., Kumashiro, M., . . Higgins, E. T. (2013). Opposites fit: Regulatory focus complementarity and relationship wellbeing. Social Cognition, 31(1), 1-14. https://doi.org/10.1521/soco.2013.31.1.1

Brenninkmeijer, V., \& Hekkert-Koning, M. (2015). To craft or not to craft: The relationships between regulatory focus, job crafting and work outcomes. Career Development International, 20(2), 147-162.

https://doi.org/10.1108/CDI-12-2014-0162 
Browne, M. W., \& Cudeck, R. (1993). Alternative ways of assessing model fit. In K. A. Bollen, \& J. S. Long (Eds.), Testing structural equation models (pp. 1-9). CA: Sage.

Brunstein, J. C., Schultheiss, O. C., \& Grässman, R. (1998). Personal goals and emotional well-being: The moderating role of motive dispositions. Journal of Personality and Social Psychology, 75, 494-508. https://doi.org/10.1037/0022-3514.75.2.494

Bull Schaefer, R. A., \& Palanski, M. E. (2014). Emotional contagion at work: An in-class experiential activity. Journal of Management Education, 38(4), 533-559. https://doi.org/10.1177/1052562913489030

Bullough, R. V., Jr., \& Hall-Kenyon, K. M. (2012). On teacher hope, sense of calling, and commitment to teaching. Teacher Education Quarterly (Spring), 7-27.

Cardador, M. T., \& Caza, B. B. (2012.) Relational and identity perspectives on healthy versus unhealthy pursuit of callings. Journal of Career Assessment, 20, 338-353. https://doi.org/10.1177/1069072711436162

Case, C. R., Bae, K. K., \& Maner, J. K. (2018). To lead or to be liked: When prestige-oriented leaders prioritize popularity over performance. Journal of Personality and Social Psychology, 115(4), 657-676. https://doi.org/10.1037/pspi0000138

Diener, E. (2000). Subjective well-being: Science of happiness and a proposal for a national index. American Psychologist, 55, 34-43. https://doi.org/10.1037/0003-066X.55.1.34

Dik, B. J., \& Duffy, R. D. (2009). Calling and vocation at work: Definitions and prospects for research and practice. The Counseling Psychologist, 37(3), 424-450. https://doi.org/10.1177/0011000008316430

Dik, B. J., \& Shimizu, A. B. (2019). Multiple meaning of calling: Next steps for studying an evolving construct. Journal of Career Assessment, 27(2), 323-336. https://doi.org/10.1177/1069072717748676

Dill, J., Erickson, R. J., \& Diefendorff, J. M. (2016). Motivation in caring labor: Implications for the well-being and employment outcomes of nurses. Social Science and Medicine, 167, 99-106. https://doi.org/10.1016/j.socscimed.2016.07.028

Dreher, D. E., Holloway, K. A., \& Schoenfelder, E. (2007). The vocation identity questionnaire: Measuring the sense of calling. Research in the Social Scientific Study of Religion, 18, 99-120. https://doi.org/10.1163/ej.9789004158511.i-301.42

Duffy, R. D., Bott, E. M., Allan, B. A., Torrey, C. L., \& Dik, B. J. (2012). Perceiving a calling, living a calling, and job satisfaction: Testing a moderated, multiple mediator model. Journal of Counseling Psychology, 59(1), 50-59. https://doi.org/10.1037/a0026129

Ecclestone, K., \& Hayes, D. (2009). Changing the subject: The educational implications of developing emotional wellbeing, Oxford Review of Education, 35(3), 371-389. https://doi.org/10.1080/03054980902934662

Elangovan, A. R., Pinder, C. C., \& McLean, M. (2010). Callings and organizational behavior. Journal of Vocational Behavior, 76, 428-440. https://doi.org/10.1016/j.jvb.2009.10.009

Emmons, R. A., \& Kaiser, H. A. (1996). Goal orientation and emotional well-being: Linking goals and affect through the self. In L. L. Martin \& A. Tesser (Eds.), Striving and feeling: Interactions among goals, affect, and self-regulation (pp. 79-98). Hillsdale, NJ, US: Lawrence Erlbaum Associates, Inc.

Green, P. I., Finkel, E. J., Fitzsimons, G. M., \& Gino, F. (2017). The energizing nature of work engagement: Toward a new need-based theory of work motivation. Research in Organizational Behavior, 37, 1-18. https://doi.org/10.1016/j.riob.2017.10.007

Hall, D. T., \& Chandler, D. E. (2004). Psychological success: When the career is a calling. Journal of Organizational Behavior, 25, 1-22.

Higgins, E. T. (1998). Promotion and prevention: Regulatory focus as a motivational principle. In M. P. Zanna (Ed.), Advances in experimental social psychology, Vol. 30 (pp. 1-46). NY: Academic Press. https://doi.org/10.1016/S0065-2601(08)60381-0

Higgins, E. T. (2000). Making a good decision: Value from fit. American Psychologist, 55, 1217-1230. https://doi.org/10.1037/0003-066X.55.11.1217

Higgins, E. T., Friedman, R. S., Harlow, R. E., Idson, L. C., Ayduk, O. N., \& Taylor, A. (2001). Achievement orientations from subjective histories of success: Promotion pride versus prevention pride. European Journal of Social Psychology, 31, 3-23. https://doi.org/10.1002/ejsp.27

Hooper, D., Coughlan, J., \& Mullen, M. R. (2008). Structural equation modelling: Guidelines for determining model 
fit. Electronic Journal of Business Research Methods, 6(1), 53-60.

Johnson, R. E., King, D. D., Lin, S. H., Scott, B. A., Walker, E. M. J., \& Wang, M. (2017). Regulatory focus trickle-down: How leader regulatory focus shapes follower regulatory focus and behavior. Organizational Behavior and Human Decision Processes, 140, 29-45. https://doi.org/10.1016/j.obhdp.2017.03.002

Kang, D. (2009). An ideal type of the image of teacher charging the moral studies. Korea Society for Moral \& Ethics Education Association. The 77th Conference. Seoul, South Korea: Seoul National University.

Kern, M. L., Waters, L., Adler, A., \& White, M. (2014). Assessing employee wellbeing in schools using a multifaceted approach: Associations with physical health, life satisfaction, and professional thriving. Psychology, 5, $500-513$. https://doi.org/10.4236/psych.2014.56060

Kim, J., Campbell, T. H., Shepherd, S., \& Kay, A. C. (2019). Understanding contemporary forms of exploitation: Attributions of passion serve to legitimize the poor treatment of workers. Journal of Personality and Social Psychology. Advance online publication. https://doi.org/10.1037/pspi0000190

Kooij, D. T., Bal, P. M., \& Kanfer, R. (2014). Future time perspective and promotion focus as determinants of intraindividual change in work motivation. Psychology and Aging, 29(2), 319-328. https://doi.org/10.1037/a0036768

Kooij, D. T., Tims, M., \& Kanfer, R. (2015). Successful aging at work: The role of job crafting. In P. M. Ball, T. A. M. Kooij, D. M. Rousseau (Eds.), Aging workers and the employee-employer relationship (pp. 145-161). NY: Springer International Publishing. https://doi.org/10.1007/978-3-319-08007-9_9

Koopmann, J. M., Lanaj, K., Bono, J. E., \& Campana, K. L. (2016). Daily shifts in regulatory focus: The influence of work events and implications for employee well-being. Journal of Organizational Behavior, 37, 1293-1316. https://doi.org/10.1002/job.2105

Korean Educational Development Institute (2018). What influences teachers' stress? 2018 KEDI BRIFE, 7. Sejong: Korean Ministry of Education.

Korean Educational Development Institute. (2017). Educational statistics analysis: K-12 educational Statistics. Sejong: Korean Ministry of Education.

Lanaj, K., Chang, C. H., \& Johnson, R. E. (2012). Regulatory focus and work-related outcomes: A meta-analysis. Psychological Bulletin, 138, 998-1034. https://doi.org/10.1037/a0027723

LeDoux, J. E. (1996). The Emotional Brain. NY: Simon and Schuster.

Lee, H. (2017). Development and initial validation of the Korean job crafting scale. Journal of Korea Academia-Industrial Cooperation Society, 18(10), 611-623.

Lichtenthaler, P. W., \& Fischbach, A. (2019). A meta-analysis on promotion-and prevention-focused job crafting. European Journal of Work and Organizational Psychology, 28(1), 30-50. https://doi.org/10.1080/1359432X.2018.1527767

Lockwood, P., Jordan, C. H., \& Kunda, Z. (2002). Motivation by positive or negative role models: Regulatory focus determines who will best inspire us. Journal of Personality and Social Psychology, 83(4), 854-864. https://doi.org/10.1037/0022-3514.83.4.854

McLaughlin, C. (2008). Emotional well-being and its relationship to schools and classrooms: A critical reflection, British Journal of Guidance \& Counselling, 36(4), 353-366. https://doi.org/10.1080/03069880802364486

Mottet, T., P., \& Beebe, S. A. (2000). Emotional contagion in the classroom: An examination of how teacher and student emotions are related. Paper presented at the Annual Meeting of the National Communication Association (86 ${ }^{\text {th }}$, Seattle, WA).

OECD (2014). TALIS 2013 results: An international perspective on teaching and learning. https://doi.org/10.1787/9789264196261-en

Richardson, P. W., \& Watt, H. M G. (2006). Who chooses teaching and why? Profiling characteristics and motivations across there Australian universities. Asia-Pacific Journal of Teacher Education, 34(1), 27-56. https://doi.org/10.1080/13598660500480290

Rudd, M., Aaker, J., \& Norton, M. I. (2014). Getting the most out of giving: Concretely framing a prosocial goal maximizes happiness. Journal of Experimental Social Psychology, 54, 11-24. https://doi.org/10.1016/j.jesp.2014.04.002

Rudolph, C. W., Katz, I. M., Lavigne, K. N., \& Zacher, H. (2017). Job crafting: A meta-analysis of relationships with 
individual differences, job characteristics, and work outcomes. Journal of Vocational Behavior, 102, 112-138. https://doi.org/10.1016/j.jvb.2017.05.008

Shin, H. (2019, May 13). "I just can’t seem to get motivated to teach", teachers' extremely low morale. University Journal. Retrieved from http://www.dhnews.co.kr/

Shin, J., \& Grant, A. (2018). Bored by interest: Intrinsic motivation in one task can reduce performance on other tasks. Academy of Management Journal (online version). https://doi.org/10.5465/amj.2017.0735

Tyng, C. M., Amin, H. U., Saad, M. N. M., \& Malik, A. S. (2017). The influences of emotion on learning and memory. Frontiers in Psychology, 8, 1454. https://doi.org/10.3389/fpsyg.2017.01454

Um, B., Joo, H., \& Her, D. (2018). The relationship between elementary school teachers' work motivation and well-being: The mediating effects of principal leadership and work stress. International Journal of Social Science Studies, 6(12), 67-78. https://doi.org/10.11114/ijsss.v6i12.3762

Vallerand, R. J., Blanchard, C., Mageau, G. A., Koestner, R., Ratelle, C., Léonard, M., ... Marsolais, J. (2003). Les passions de l'ame: on obsessive and harmonious passion. Journal of personality and social psychology, 85(4), 756-767. https://doi.org/10.1037/0022-3514.85.4.756

van Vuuren, M. (2017). Called to do meaningful work: A blessing or a curse? Christian Higher Education, 16(1-2), 47-54. https://doi.org/10.1080/15363759.2017.1251245

Wolf, E. B., Lee, J. J., Sah, S., \& Brooks, A. W. (2016). Managing perceptions of distress at work: Reframing emotion as passion. Organizational Behavior and Human Decision Processes 137, 1-12. https://doi.org/10.1016/j.obhdp.2016.07.003

Wrzesniewski, A., \& Dutton, J. E. (2001). Crafting a job: Revisioning employees as active crafters of their work. Academy of Management Review, 26(2), 179-201. https://doi.org/10.5465/amr.2001.4378011

Wrzesniewski, A., LoBuglio, N., Dutton, J. E., \& Berg, J. M. (2013). Job crafting and cultivating positive meaning and identity in work. Advances in Positive Organizational Psychology, 1, 281-302. https://doi.org/10.1108/S2046-410X(2013)0000001015

Zhang, C., Mayer, D. M., \& Hwang, E. (2018). More is less: Learning but not relaxing buffers deviance under job stressors. Journal of Applied Psychology, 103(1), 123-136. https://doi.org/10.1037/apl0000264

\section{Copyrights}

Copyright for this article is retained by the author(s), with first publication rights granted to the journal.

This is an open-access article distributed under the terms and conditions of the Creative Commons Attribution license which permits unrestricted use, distribution, and reproduction in any medium, provided the original work is properly cited. 